\title{
Clinical Usefulness of the Cardio-Ankle Vascular Index as a Predictor of Primary Cardiovascular Events in Patients With Chronic Kidney Disease
}

\author{
Takashi Hitsumoto
}

\begin{abstract}
Background: The cardio-ankle vascular index (CAVI) is a physiologic marker reflecting arterial function. There have been no prospective studies investigating the relationship between CAVI and cardiovascular events in patients with chronic kidney disease (CKD). The aim of this prospective study was to assess the clinical usefulness of CAVI as a predictor of primary cardiovascular events in patients with CKD.
\end{abstract}

Methods: The study enrolled 460 outpatients with CKD but no history of cardiovascular disease (152 men and 308 women; mean \pm standard deviation age, $74 \pm 12$ years). Patients were assigned to one of three groups: low (L, CAVI < 9; $\mathrm{n}=100)$, medium (M, CAVI $9-10 ; \mathrm{n}=199)$, or high (H, CAVI $>10 ; \mathrm{n}=161)$. The utility of the CAVI as a predictor of primary cardiovascular events was evaluated.

Results: During the follow-up period (median 60.1 months), major adverse cardiovascular events (MACE) occurred in 91 cases (L, 8 (8.0\%); M, 31 (15.6\%); H, 52 (32.3\%); P < 0.001, log-rank test). On multivariate Cox regression analysis, the risk for a MACE was significantly higher in group $\mathrm{H}$ than in non-group $\mathrm{H}$ (hazard ratio, 2.04; $95 \%$ confidence interval, $1.31-3.02 ; \mathrm{P}<0.01)$. A CAVI cut-off of 9.7 yielded the largest area under the curve, 0.701 (95\% confidence interval: $0.657-0.743, \mathrm{P}<0.001$ ), indicating a sensitivity of $74.0 \%$ and a specificity of $59.6 \%$ for discriminating between those who did and did not experience a MACE during follow-up.

Conclusions: The results of this study showed that a high CAVI is a predictor of primary cardiovascular events in patients with CKD.

Keywords: Cardio-ankle vascular index; Chronic kidney disease; Primary cardiovascular events; Oxidative stress; Advanced glycation end products; Renin-angiotensin system inhibitor

Manuscript submitted September 20, 2018, accepted October 12, 2018

Hitsumoto Medical Clinic, 2-7-7, Takezakicyou, Shimonoseki City, Yamaguchi, 750-0025, Japan. Email: thitsu@jcom.home.ne.jp

doi: https://doi.org/10.14740/jocmr3631

\section{Introduction}

In recent years, the prevalence of chronic kidney disease (CKD) has increased because of both life-extending treatment and the increased incidence of life style-related disease such as hypertension, type 2 diabetes mellitus, and dyslipidemia [1,2]. CKD is an important risk factor not only for end-stage renal disease but also for cardiovascular disease (CVD) [3, 4]. Complications of CVD in patients with CKD are associated with a poor prognosis $[5,6]$. Therefore, for patients with CKD, it is crucial to be alert to risk factors for cardiovascular events and to consider treatment to prevent them.

Arterial dysfunction is an important risk factor for cardiovascular events. Among physiologic markers of arterial function, the cardio-ankle vascular index (CAVI) is a novel marker of atherosclerosis that reflects systemic arterial stiffness in vessels such as the aorta and the femoral and tibial arteries [7]. This stiffness parameter is reported to be independent of the blood pressure during measurement. In addition, CAVI is thought to reflect endothelial function $[8,9]$. Several clinical studies have indicated the clinical significance of CAVI in relation to CKD [10-12]. However, there has been no prospective study of the relationship between CAVI and cardiovascular events in patients with CKD. Therefore, this study was designed to clarify the clinical usefulness of CAVI as a predictor of primary cardiovascular events in patients with CKD.

\section{Materials and Methods}

\section{Participants}

Between June 2011 and December 2013, 460 outpatients (152 men (33.0\%) and 308 women (67.0\%)) with CKD but no history of cardiovascular events were prospectively enrolled at the Hitsumoto Medical Clinic, Yamaguchi, Japan. Estimated glomerular filtration rate (eGFR) was calculated using the adjusted Modification of Diet in Renal Disease Study equation, as proposed by the working group of the Japanese Chronic Kidney Disease Initiative [13]. The definition of CKD for selection of participants was an eGFR from 15 to $59 \mathrm{~mL} / \mathrm{min} / 1.73 \mathrm{~m}^{2}$. The mean age ( \pm standard deviation) was 
$74 \pm 12$ years. CAVI was measured as described below, after which the participants were assigned to one of three groups, those with a low $(\mathrm{L},<9 ; \mathrm{n}=100)$, medium $(\mathrm{M},=9-10 ; \mathrm{n}$ $=199)$, or high $(\mathrm{H},>10 ; \mathrm{n}=161)$ CAVI. Cut-off levels of CAVI were determined by previous studies [14]. The study protocol was approved by Local Ethics Committee of Hitsumoto Medical Clinic, and informed consent was obtained from all participants.

\section{Measurement of CAVI}

The CAVI was measured using a commercial device (Vasera; Fukuda Denshi, Tokyo, Japan) according to previously described methods [7]. Briefly, the brachial and ankle pulse waves were determined using inflatable cuffs with the pressure maintained between 30 and $50 \mathrm{~mm} \mathrm{Hg}$ to ensure that the cuff pressure had a minimal effect on the systemic hemodynamics. Blood and pulse pressures were determined simultaneously with the subjects lying supine, after they had first rested for 10 min in a quiet room. The CAVI recorded for the study was the mean of the left and right values. CAVI was calculated using the following formula: $\mathrm{CAVI}=\mathrm{a}\left\{(2 \rho / \Delta \mathrm{P}) \times \ln (\mathrm{Ps} / \mathrm{Pd}) \mathrm{PWV}^{2}\right\}$ $+\mathrm{b}$, where $\mathrm{a}$ and $\mathrm{b}$ are constants, $\rho$ is blood density, $\Delta \mathrm{P}$ is Ps $\mathrm{Pd}$, Ps is systolic blood pressure, $\mathrm{Pd}$ is diastolic blood pressure, and PWV is pulse wave velocity.

\section{Evaluation of clinical parameters}

Body mass index was calculated as the weight in kilograms divided by the square of the height in meters. Obesity was defined by the Japanese criteria of body mass index $\geq 25 \mathrm{~kg} /$ $\mathrm{m}^{2}$. Current smoking was defined as smoking at least one cigarette per day during the previous 28 days. Hypertension was defined as systolic blood pressure $\geq 140 \mathrm{~mm} \mathrm{Hg}$, diastolic blood pressure $\geq 90 \mathrm{~mm} \mathrm{Hg}$, or the use of antihypertensive medication. Dyslipidemia was defined as a low-density lipoprotein cholesterol level $\geq 140 \mathrm{mg} / \mathrm{dL}$, a high-density lipoprotein cholesterol level $\leq 40 \mathrm{mg} / \mathrm{dL}$, a triglyceride level $\geq$ $150 \mathrm{mg} / \mathrm{dL}$, or the use of antidyslipidemic medication. Diabetes mellitus was defined as a fasting blood glucose level $\geq$ $126 \mathrm{mg} / \mathrm{dL}$ or the use of antidiabetic medication. Skin autofluorescence (AF) reflects pentosidine, a major component of advanced glycation end products (AGEs) in tissues. It was measured using a commercial device (AGE Reader; DiagnOptics, Groningen, Netherlands), as previously described [15]. AF was defined as the average light intensity per nanometer between $300 \mathrm{~nm}$ and $420 \mathrm{~nm}$. Skin AF levels were expressed in arbitrary units. The following blood or urine parameters were measured: serum lipid concentrations, plasma glucose concentrations, derivatives of reactive oxygen metabolites (d-ROMs), and urinary albumin concentrations. Blood samples were collected from the antecubital vein in the morning after $12 \mathrm{~h}$ of fasting, and urine samples were collected on the same day. Total cholesterol and triglyceride concentrations were measured using standard enzymatic methods. Highand low-density lipoprotein cholesterol concentrations were measured using selective inhibition and Friedewald's formula, respectively [16]. Participants with a serum triglyceride concentration $\geq 400 \mathrm{mg} / \mathrm{dL}$ were excluded from the analysis, given the limitations of this method. Glucose concentrations were measured by the glucose oxidase method. As a marker of oxidative stress in vivo [17], the d-ROMs test was performed using a commercial kit (Diacron, Grosseto, Italy). Urinary albumin concentration was measured using a commercial kit (Siemens/Bayer DCA 2000+ Analyzer, Siemens Healthineers, Tokyo, Japan).

\section{Follow-up}

The study follow-up period ended in May 2018. The endpoint was a major adverse cardiovascular event (MACE), a composite of cardiovascular death, nonfatal myocardial infarction, nonfatal ischemic stroke and hospital admission for heart failure.

\section{Statistical analysis}

Data were analyzed using Stat View-J 5.0 (HULINKS, Tokyo, Japan) and MedCalc for Windows version 14.8.1 (MedCalc Software, Ostend, Belgium). Data are presented as mean \pm standard deviation. One-way analysis of variance and the Kruskal-Wallis test were used for comparisons among the three groups. Post-hoc testing was performed using Fisher's protected least significant differences or the Mann-Whitney U-test with the Bonferroni correction. Event-free survival rate curves were plotted using Kaplan-Meier analysis, and the differences between the curves were evaluated using the log-rank test. Multivariate analysis was performed using multivariate Cox regression analysis. Receiver operating characteristic (ROC) curves were constructed, and the Youden Index was used to determine the optimal cut-off for CAVI for predicting a MACE. $\mathrm{P}<0.05$ was considered statistically significant.

\section{Results}

Table 1 presents the characteristics of the participants at study entry, and the dot graph of CAVI is shown in Figure 1. The mean CAVI for groups L, M, and H was 8.4 (range; 7.5 - 8.9), 9.5 (range; 9.0 - 10.0), and 10.9 (range; 10.1 - 13.7), respectively. The eGFR level was significantly lower in group $\mathrm{H}$ than in group $\mathrm{M}$ or group L. The following factors were significantly higher in group $\mathrm{H}$ than in group $\mathrm{M}$ or L: fasting blood glucose levels, skin AF, d-ROMs, and urinary albumin concentrations. Figure 2 shows the Kaplan-Meier curve for the incidence of MACE. The median follow-up was 60.1 months (range, 2 - 84 months). During follow-up, 91 participants experienced at least one MACE (L, 8 cases $(8.0 \%))$; M, 31 cases $(15.6 \%))$; H, 52 cases $(32.3 \%))$. Group H had a significantly higher incidence of MACE compared with groups $\mathrm{M}$ and $\mathrm{L}$ (log-rank test, $\mathrm{P}<0.001)$. Table 2 presents the clinical vari- 
Table 1. Characteristics of Patients

\begin{tabular}{|c|c|c|c|c|c|}
\hline & Overall & Group L & Group M & Group H & P value \\
\hline n (male/female) & $460(152 / 308)$ & $100(25 / 75)$ & $199(63 / 136)$ & $161(64 / 97)^{* * *}$ & $<0.05$ \\
\hline Age (yrs) & $74 \pm 12$ & $71 \pm 10$ & $73 \pm 11$ & $75 \pm 13^{* *}$ & $<0.05$ \\
\hline CAVI & $9.7 \pm 1.1$ & $8.4 \pm 0.5$ & $9.5 \pm 0.2 *$ & $10.9 \pm 0.8^{* \#}$ & $<0.001$ \\
\hline Obesity, n (\%) & $136(30)$ & $27(27)$ & $56(28)$ & $53(33)$ & 0.503 \\
\hline $\mathrm{SBP}(\mathrm{mm} \mathrm{Hg})$ & $142 \pm 16$ & $138 \pm 17$ & $141 \pm 16$ & $144 \pm 13 * *$ & $<0.05$ \\
\hline DBP (mm Hg) & $87 \pm 11$ & $85 \pm 11$ & $88 \pm 11 * * *$ & $89 \pm 11^{* *}$ & $<0.05$ \\
\hline Dyslipidemia, n (\%) & $320(70)$ & 77 (77) & $133(67)$ & $110(68)$ & 0.181 \\
\hline Diabetes mellitus, n (\%) & $155(34)$ & $24(24)$ & $65(33)$ & $66(41)^{* *}$ & $<0.05$ \\
\hline LDL cholesterol (mg/dL) & $129 \pm 35$ & $130 \pm 30$ & $126 \pm 35$ & $133 \pm 36$ & 0.246 \\
\hline Triglyceride (mg/dL) & $138 \pm 63$ & $148 \pm 72$ & $139 \pm 62$ & $130 \pm 57$ & 0.073 \\
\hline HDL cholesterol (mg/dL) & $59 \pm 15$ & $58 \pm 14$ & $60 \pm 15$ & $59 \pm 15$ & 0.462 \\
\hline FBG (mg/dL) & $110 \pm 22$ & $107 \pm 20$ & $108 \pm 20$ & $116 \pm 25^{* * \# \#}$ & $<0.001$ \\
\hline Skin AF (AU) & $2.7 \pm 0.5$ & $2.5 \pm 0.5$ & $2.7 \pm 0.5^{* * *}$ & $2.9 \pm 0.5^{* \#}$ & $<0.001$ \\
\hline d-ROMs test (U.Carr) & $328 \pm 86$ & $307 \pm 88$ & $324 \pm 82$ & 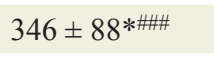 & $<0.001$ \\
\hline U-Alb (mg/g Cr) & $1.5 \pm 0.6$ & $1.4 \pm 0.5$ & $1.5 \pm 0.6$ & $1.6 \pm 0.6^{* \# \# \#}$ & $<0.01$ \\
\hline \multicolumn{6}{|l|}{ Medication } \\
\hline RAS inhibitor, n (\%) & $164(36)$ & $36(36)$ & $63(32)$ & $65(40)$ & 0.229 \\
\hline
\end{tabular}

Continuous values are mean \pm SD. CAVI: cardio-ankle vascular index; SBP: systolic blood pressure; DBP: diastolic blood pressure; eGFR: estimated glomerular filtration rate; LDL: low-density lipoprotein; HDL: high-density lipoprotein; FBG: fasting blood glucose; AF: autofluorescence; d-ROMs: derivatives of reactive oxygen metabolites; U-Alb: urinary albumin; RAS: renin-angiotensin system. ${ }^{*} P<0.001$ vs. Group L; **P < 0.01 vs. Group L; ${ }^{* * *} \mathrm{P}<0.05$ vs. Group L; $\mathrm{P}<0.001$ vs. Group M; ${ }^{\#} \mathrm{P}<0.01$ vs. Group M; ${ }^{\# \# P}<0.05$ vs. Group M.

ables at study entry of all the participants, comparing those who experienced MACEs with those who did not. Age, current smoking status, prevalence of hypertension, systolic blood pressure, prevalence of diabetes mellitus, fasting blood glucose concentrations, skin AF, d-ROMs, and urinary albumin concentration were considerably higher in participants who had a MACE than in those who did not. The eGFR levels and use of renin-angiotensin system (RAS) inhibitors or statins were considerably lower. Table 3 presents the results of the multivariate Cox regression analysis for the MACE. A total of 11 variables were significant factors for MACE on univariate analysis or in a check of multicollinearity among the variables. Of these 11, six variables (CAVI, a CAVI $>10$, diabetes mellitus, age, skin AF, d-ROMs, and RAS-inhibitor use) had a significant hazard ratio for MACE. Figure 3 shows the ROC curve analysis for the incidence of MACE based on CAVI. A cut-off value of 9.7 yielded the largest area under the curve, 0.701 (95\% confidence interval: $0.657-0.743, \mathrm{P}<0.001)$. This indicated a sensitivity of $74.0 \%$ and specificity of $59.6 \%$ to discriminate between those who did and did not have a MACE during follow-up.

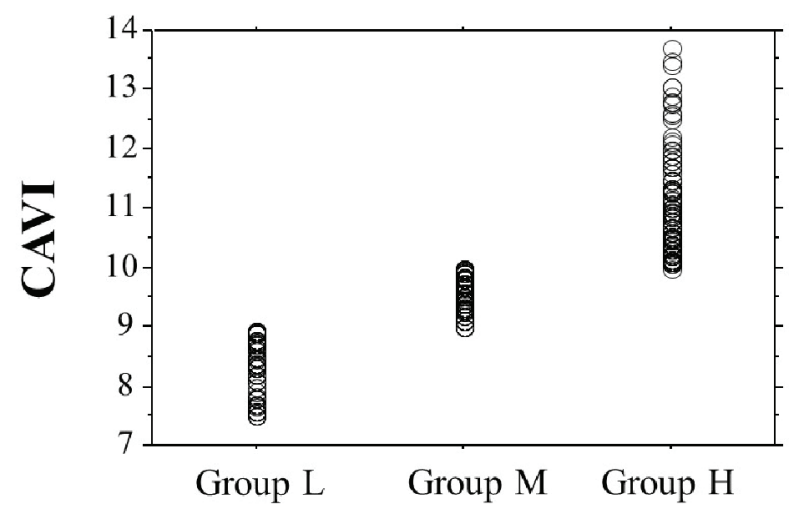

Figure 1. The dot graph of CAVI. CAVI: cardio-ankle vascular index. 


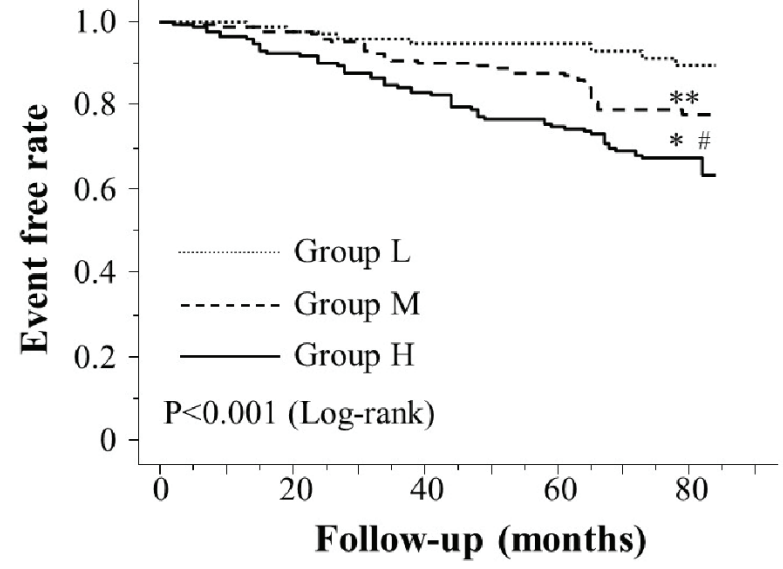

Figure 2. Kaplan-Meier curve for the incidence of major adverse cardiovascular events. The Kaplan-Meier curve confirmed that group $\mathrm{H}$ had a significantly higher incidence of major adverse cardiovascular events compared with groups $\mathrm{M}$ and $\mathrm{L}$ (log-rank test, $\mathrm{P}<0.001)$. ${ }^{*} \mathrm{P}<0.001$ vs. group $L$, ${ }^{* *} P=0.112$ vs. group $L$, ${ }^{\#} P<0.001$ vs. group $M$.
Table 3. Multivariate Cox Regression Analysis for Major Adverse Cardiovascular Events

\begin{tabular}{llll} 
& HR & $\mathbf{9 5 \%}$ CI & P value \\
\hline Diabetes mellitus & 2.50 & $1.38-4.60$ & $<0.01$ \\
Group H (vs non-Group H) & 2.04 & $1.31-3.02$ & $<0.01$ \\
Age $(\geq 75 y r s)$ & 1.81 & $1.03-3.22$ & $<0.05$ \\
Skin AF $(\geq 3.0 \mathrm{AU})$ & 1.64 & $1.09-2.63$ & $<0.05$ \\
d-ROMs test $(\geq 330 \mathrm{U}$. Carr) & 1.61 & $1.01-2.79$ & $<0.05$ \\
RAS inhibitor & 0.58 & $0.23-0.99$ & $<0.05$ \\
Current smoker & 1.58 & $0.93-2.69$ & 0.089 \\
Albuminuria & 1.39 & $0.92-2.11$ & 0.137 \\
Statin & 0.70 & $0.42-1.15$ & 0.178 \\
eGFR $\left(<30 \mathrm{~mL} / \mathrm{min} / 1.73 \mathrm{~m}^{2}\right)$ & 1.40 & $0.79-2.53$ & 0.255 \\
Hypertension & 1.26 & $0.73-2.16$ & 0.399 \\
\hline
\end{tabular}

HR: hazard ratio; $\mathrm{Cl}$ : confidence interval; AF: autofluorescence; dROMs: derivatives of reactive oxygen metabolites; RAS: renin-angiotensin system; eGFR: estimated glomerular filtration rate.

Table 2. Clinical Parameters at Registration of Patients With and Without Major Adverse Cardiovascular Events

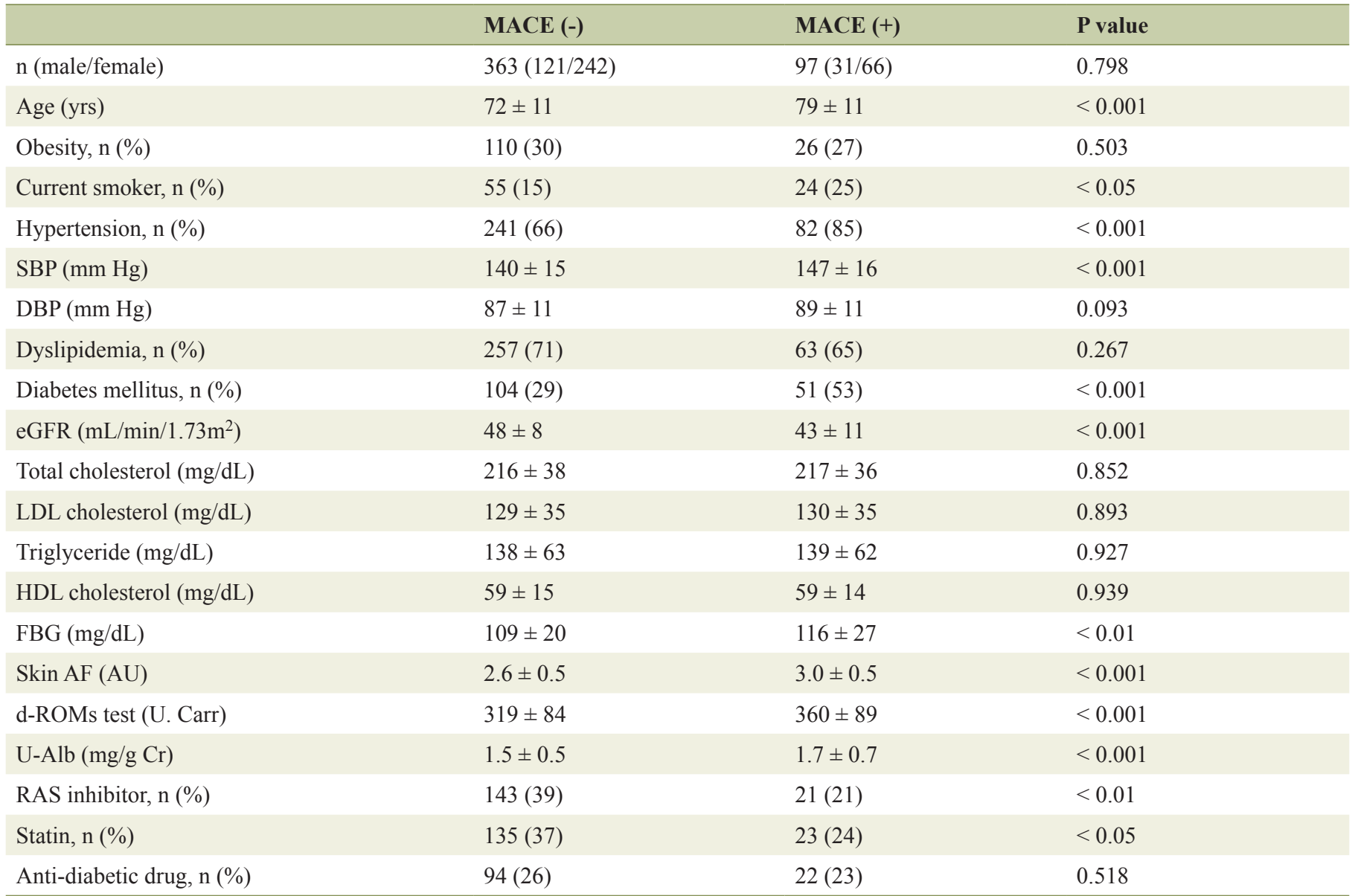

Continuous values are mean \pm SD. SBP: systolic blood pressure; DBP: diastolic blood pressure; eGFR: estimated glomerular filtration rate; LDL: low-density lipoprotein; HDL: high-density lipoprotein; FBG: fasting blood glucose; AF: autofluorescence; d-ROMs: derivatives of reactive oxygen metabolites; U-Alb: urinary albumin, RAS: renin-angiotensin system. 


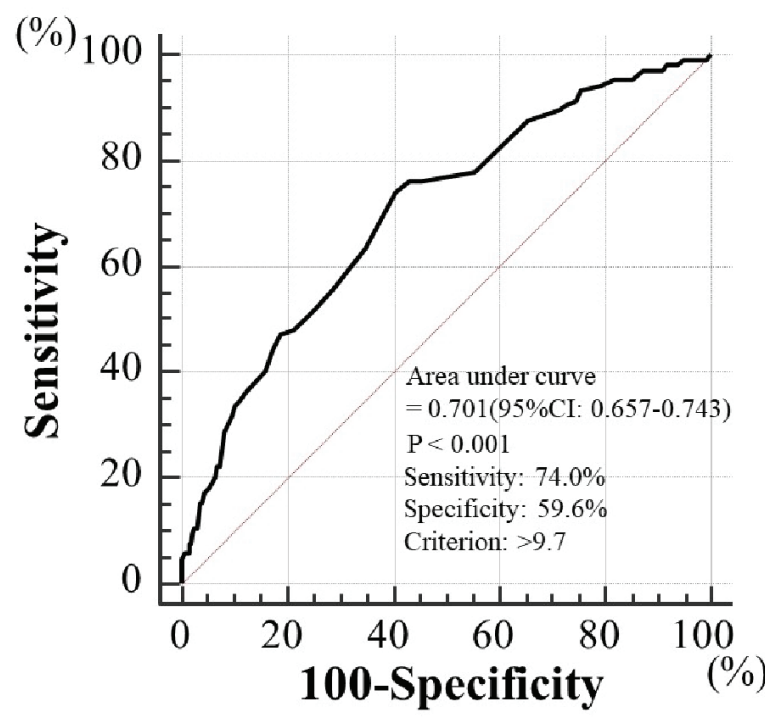

Figure 3. Prediction of major adverse cardiovascular events at followup period using CAVI. A cut-off value for CAVI of 9.7 yielded the largest area under the curve of 0.701 (95\% confidence interval: $0.657-0.743$, $P<0.001$ ), with a sensitivity of $74.0 \%$ and specificity of $59.6 \%$ for discriminating between those who did and did not experience major adverse cardiovascular events during the follow-up period. CAVI: cardioankle vascular index.

\section{Discussion}

Previous studies have indicated the association of aging, diabetes mellitus, and CVD with CKD [18, 19]. Consistent with these previous findings, this study confirmed these traditional CVD risk factors as independent predictors of a MACE. The results of the present study also found that a high CAVI was a predictor of a MACE in patients with CKD. In addition, the results of the d-ROMs test, as an in vivo marker of oxidative stress, and skin AF, as a marker of tissue AGEs, were also independent predictors of a MACE. These novel CVD risk factors were significantly associated with a high CAVI.

Several clinical studies have reported the relationship between arterial dysfunction, including increased arterial stiffness or endothelial dysfunction, and the incidence of cardiovascular events in patients with CKD [20-22]. The results of the present study, demonstrating a significant association between CAVI and MACEs, imply that arterial dysfunction is an important target for prevention of primary cardiovascular events in patients with CKD. This study found that a CAVI > 10 was selected as an independent predictor of MACE among all the explanatory variables we analyzed. In addition, ROC curve analysis for the incidence of MACE indicated that a cut-off value for CAVI of 9.7 yielded the largest area under the curve $(0.701)$ for discriminating between those who did and did not experience MACE. Previous studies reported that the CAVI could be improved by interventions such as lifestyle modification or medication [23-26]. The results of the present study suggest that aggressive intervention should be undertaken for patients with CKD whose CAVI is 10 or higher with a view to decreasing cardiovascular events. Deterioration of markers of kidney function such as eGFR or albuminuria is reported to be an important risk factor for cardiovascular events [4]. However, multivariate analysis in this study indicated that these renal function variables were not independently predictive of a MACE, even though they were significantly associated with such events on univariate analysis. However, eGFR and albuminuria were significantly associated with CAVI. Previous studies also indicated that an increase in the CAVI is closely associated with a decreased eGFR or increased albuminuria $[10,27]$. Thus, these results can be interpreted that increase of CAVI in the background of decrease in eGFR or albuminuria of CKD patients acts crucial role in the incidence of CVD.

It is no doubt a fact that oxidative stress is an important factor in the pathogenesis of CVD. Various oxidative stress markers have been reported to be associated clinically with CVD, and several clinical studies have indicated the clinical usefulness of measuring d-ROMs as a risk factor for cardiovascular events [28-30]. The results of the present study also found that elevated d-ROM levels were a predictor of primary cardiovascular events in patients with CKD. This study found that higher d-ROM levels were associated with a high CAVI. Previous studies have reported that anti-oxidant medications result in a reduced CAVI $[25,31,32]$. Thus, findings of the present study again are consistent with the notion that oxidative stress increases cardiovascular events in patients with CKD, and this may be reflected in an elevated CAVI. This raises the possibility of reducing CAVI with anti-oxidant medication and, therefore, the incidence of primary cardiovascular events.

Recent basic and clinical studies have emphasized the important role played by AGEs in various diseases, such as the complications of diabetes, CKD, and CVD [33]. In addition, researchers have reported that increased skin AF is a cardiovascular risk factor [34-37]. The results of this study also indicate that a high skin $\mathrm{AF}$ is an independent predictor of primary cardiovascular events in patients with CKD. In addition, a high skin AF level had a significant positive correlation with CAVI, suggesting that accumulation of AGEs in arterial vessel walls contributes to arterial dysfunction in patients with CKD. Genevieve et al examined the relationship between skin AF and hemoglobin Alc $(\mathrm{HbAlc})$ levels, which reflect the preceding 1- to 2-month glucose levels [38]. They measured HbA1c levels every 6 months and found that the skin AF level was significantly related to the preceding five and 10 mean $\mathrm{HbAlc}$ levels. Isami et al reported that lifestyle habits such as physical activity, nonsmoking, adequate sleep, low mental stress level, eating breakfast, and abstaining from sugary foods were each independently associated with lower skin AF levels [39]. Thus, long-term glucose control and good life style habits are important to maintain lower skin AF levels and a lower CAVI.

It is well known that the RAS system is an important factor in the pathogenesis of both CKD and CVD. In fact, RAS inhibitors are clinically shown to suppress the progression of CKD and the incidence of CVD events [40, 41]. In addition, administration of RAS inhibitors has been shown to reduce the incidence of cardiovascular events in patients with CKD [42, 43]. The results of this study also indicate that the use of RAS inhibitors was independently associated with fewer MACEs in patients with CKD. Several studies have in fact reported that 
RAS inhibition is effective in improving the CAVI [32, 44, 45]. Among patients of the present study, RAS inhibitors were used in $40 \%$ of patients in group $\mathrm{H}$. Therefore, greater use of RAS inhibitors is required to improve arterial function in patients with a high CAVI, with the expectation that it will help reduce primary cardiovascular events in patients with CKD.

\section{Limitations}

This study had several limitations. First, it was conducted at a single center with a relatively small sample, so the findings cannot be generalized to all populations. Second, CAVI was measured only once at study entry. A further investigation of serial changes in CAVI in relation to primary cardiovascular events is needed. Finally, further studies of patients with a high CAVI are warranted to confirm whether interventions, such as lifestyle modification or medications, reduce the incidence of primary cardiovascular events in patients with CKD along with improvement in CAVI.

\section{Conclusions}

This study demonstrated that CAVI is a predictor of primary cardiovascular events in patients with CKD. Further studies of patients with a high CAVI are warranted to confirm whether interventions, such as lifestyle modification or medications, reduce the incidence of primary cardiovascular events in patients with CKD along with improvement of the CAVI.

\section{Conflict of Interest}

Author has no conflict of interest.

\section{Grant Support}

None.

\section{References}

1. Yamagata K, Ishida K, Sairenchi T, Takahashi H, Ohba S, Shiigai T, Narita M, et al. Risk factors for chronic kidney disease in a community-based population: a 10-year follow-up study. Kidney Int. 2007;71(2):159-166.

2. Kim KS, Park SW, Cho YW, Kim SK. Higher Prevalence and Progression Rate of Chronic Kidney Disease in Elderly Patients with Type 2 Diabetes Mellitus. Diabetes Metab J. 2018;42(3):224-232.

3. Gansevoort RT, Matsushita K, van der Velde M, Astor BC, Woodward M, Levey AS, de Jong PE, et al. Lower estimated GFR and higher albuminuria are associated with adverse kidney outcomes. A collaborative meta-analysis of general and high-risk population cohorts. Kidney Int. 2011;80(1):93-104.
4. Chronic Kidney Disease Prognosis Consortium, Matsushita K, van der Velde M, Astor BC, Woodward M, Levey AS, de Jong PE, et al. Association of estimated glomerular filtration rate and albuminuria with all-cause and cardiovascular mortality in general population cohorts: a collaborative meta-analysis. Lancet. 2010;375(9731):20732081.

5. Nikolsky E, Mehran R, Turcot D, Aymong ED, Mintz GS, Lasic Z, Lansky AJ, et al. Impact of chronic kidney disease on prognosis of patients with diabetes mellitus treated with percutaneous coronary intervention. Am J Cardiol. 2004;94(3):300-305.

6. Dan K, Miyoshi T, Nakahama M, Mizuno T, Kagawa K, Naito Y, Kawada S, et al. Impact of chronic kidney disease on cardiovascular and renal events in patients undergoing percutaneous coronary intervention with everolimuseluting stent: risk stratification with $\mathrm{C}$-reactive protein. Cardiorenal Med. 2018;8(2):151-159.

7. Shirai K, Utino J, Otsuka K, Takata M. A novel blood pressure-independent arterial wall stiffness parameter; cardio-ankle vascular index (CAVI). J Atheroscler Thromb. 2006;13(2):101-107.

8. Endo K, Saiki A, Ohira M, Miyashita Y, Shirai K. Cardioankle vascular index may reflect endothelial function in type 2 diabetes. Int J Clin Pract. 2011;65(11):1200-1201.

9. Kim KJ, Lee BW, Kim HM, Shin JY, Kang ES, Cha BS, Lee EJ, et al. Associations between cardio-ankle vascular index and microvascular complications in type 2 diabetes mellitus patients. J Atheroscler Thromb. 2011;18(4):328336.

10. Kubozono T, Miyata M, Ueyama K, Nagaki A, Hamasaki S, Kusano K, Kubozono O, et al. Association between arterial stiffness and estimated glomerular filtration rate in the Japanese general population. J Atheroscler Thromb. 2009;16(6):840-845.

11. Namikoshi T, Fujimoto S, Yorimitsu D, Ihoriya C, Fujimoto Y, Komai N, Sasaki T, et al. Relationship between vascular function indexes, renal arteriolosclerosis, and renal clinical outcomes in chronic kidney disease. Nephrology (Carlton). 2015;20(9):585-590.

12. Capusa C, Stefan G, Stancu S, Ilyes A, Dorobantu N, Mircescu G. Subclinical cardiovascular disease markers and vitamin D deficiency in non-dialysis chronic kidney disease patients. Arch Med Sci. 2016;12(5):1015-1022.

13. Imai $\mathrm{E}$, Horio $\mathrm{M}$, Nitta $\mathrm{K}$, Yamagata $\mathrm{K}$, Iseki $\mathrm{K}$, Hara $\mathrm{S}$, Ura $\mathrm{N}$, et al. Estimation of glomerular filtration rate by the MDRD study equation modified for Japanese patients with chronic kidney disease. Clin Exp Nephrol. 2007;11(1):41-50.

14. Kubota Y, Maebuchi D, Takei M, Inui Y, Sudo Y, Ikegami Y, Fuse J, et al. Cardio-Ankle Vascular Index is a predictor of cardiovascular events. Artery Res 2011;5(3):91-96.

15. Meerwaldt R, Links TP, Graaff R, Hoogenberg K, Lefrandt JD, Baynes JW, Gans RO, et al. Increased accumulation of skin advanced glycation end-products precedes and correlates with clinical manifestation of diabetic neuropathy. Diabetologia. 2005;48(8):1637-1644.

16. Friedewald WT, Levy RI, Fredrickson DS. Estimation of the concentration of low-density lipoprotein cholesterol 
in plasma, without use of the preparative ultracentrifuge. Clin Chem. 1972;18(6):499-502.

17. Cesarone MR, Belcaro G, Carratelli M, Cornelli U, De Sanctis MT, Incandela L, Barsotti A, et al. A simple test to monitor oxidative stress. Int Angiol. 1999;18(2):127-130.

18. Levey AS, de Jong PE, Coresh J, El Nahas M, Astor BC, Matsushita K, Gansevoort RT, et al. The definition, classification, and prognosis of chronic kidney disease: a KDIGO Controversies Conference report. Kidney Int. 2011;80(1):17-28.

19. Bouchi R, Babazono T, Yoshida N, Nyumura I, Toya K, Hayashi T, Hanai K, et al. Association of albuminuria and reduced estimated glomerular filtration rate with incident stroke and coronary artery disease in patients with type 2 diabetes. Hypertens Res. 2010;33(12):1298-1304.

20. Sulemane S, Panoulas VF, Bratsas A, Grapsa J, Brown EA, Nihoyannopoulos P. Subclinical markers of cardiovascular disease predict adverse outcomes in chronic kidney disease patients with normal left ventricular ejection fraction. Int J Cardiovasc Imaging. 2017;33(5):687-698.

21. Chen J, Mohler ER, 3rd, Garimella PS, Hamm LL, Xie D, Kimmel S, Townsend RR, et al. Ankle brachial index and subsequent cardiovascular disease risk in patients with chronic kidney disease. J Am Heart Assoc. 2016;5(6):e003339.

22. Moody WE, Edwards NC, Madhani M, Chue CD, Steeds RP, Ferro CJ, Townend JN. Endothelial dysfunction and cardiovascular disease in early-stage chronic kidney disease: cause or association? Atherosclerosis. 2012;223(1):86-94.

23. Iwasa T, Amiya E, Ando J, Watanabe M, Murasawa T, Komuro I. Different Contributions of Physical Activity on Arterial Stiffness between Diabetics and Non-Diabetics. PLoS One. 2016;11(8):e0160632.

24. Nagayama D, Endo K, Ohira M, Yamaguchi T, Ban N, Kawana H, Nagumo A, et al. Effects of body weight reduction on cardio-ankle vascular index (CAVI). Obes Res Clin Pract. 2013;7(2):e139-e145.

25. Miyashita Y, Endo K, Saiki A, Ban N, Yamaguchi T, Kawana H, Nagayama D, et al. Effects of pitavastatin, a 3-hydroxy-3-methylglutaryl coenzyme a reductase inhibitor, on cardio-ankle vascular index in type 2 diabetic patients. J Atheroscler Thromb. 2009;16(5):539-545.

26. Shirai K, Song M, Suzuki J, Kurosu T, Oyama T, Nagayama D, Miyashita Y, et al. Contradictory effects of beta1and alpha1- aderenergic receptor blockers on cardio-ankle vascular stiffness index (CAVI) - CAVI independent of blood pressure. J Atheroscler Thromb. 2011;18(1):4955.

27. Liu J, Liu H, Zhao H, Shang G, Zhou Y, Li L, Wang H. Descriptive study of relationship between cardio-ankle vascular index and biomarkers in vascular-related diseases. Clin Exp Hypertens. 2017;39(5):468-472.

28. Kotani K, Tsuzaki K, Taniguchi N, Sakane N. Correlation between reactive oxygen metabolites \& atherosclerotic risk factors in patients with type 2 diabetes mellitus. Indian J Med Res. 2013;137(4):742-748.

29. Masaki N, Sato A, Horii S, Kimura T, Toya T, Yasuda R, Namba T, et al. Usefulness of the d-ROMs test for prediction of cardiovascular events. Int $\mathrm{J}$ Cardiol. 2016;222:226-232.

30. Hitsumoto T. Efficacy of the reactive oxygen metabolite test as a predictor of initial heart failure hospitalization in elderly patients with chronic heart failure. Cardiol Res. 2018;9(3):153-160.

31. Nagayama D, Saiki A, Endo K, Yamaguchi T, Ban N, Kawana H, Ohira M, et al. Improvement of cardio-ankle vascular index by glimepiride in type 2 diabetic patients. Int J Clin Pract. 2010;64(13):1796-1801.

32. Miyashita Y, Saiki A, Endo K, Ban N, Yamaguchi T, Kawana H, Nagayama D, et al. Effects of olmesartan, an angiotensin II receptor blocker, and amlodipine, a calcium channel blocker, on Cardio-Ankle Vascular Index (CAVI) in type 2 diabetic patients with hypertension. J Atheroscler Thromb. 2009;16(5):621-626.

33. Nenna A, Spadaccio C, Lusini M, Ulianich L, Chello M, Nappi F. Basic and Clinical Research Against Advanced Glycation End Products (AGEs): New Compounds to Tackle Cardiovascular Disease and Diabetic Complications. Recent Adv Cardiovasc Drug Discov. 2015;10(1):10-33.

34. den Dekker MA, Zwiers M, van den Heuvel ER, de Vos LC, Smit AJ, Zeebregts CJ, Oudkerk M, et al. Skin autofluorescence, a non-invasive marker for AGE accumulation, is associated with the degree of atherosclerosis. PLoS One. 2013;8(12):e83084.

35. Hangai M, Takebe N, Honma H, Sasaki A, Chida A, Nakano $\mathrm{R}$, Togashi $\mathrm{H}$, et al. Association of advanced glycation end products with coronary artery calcification in Japanese subjects with type 2 diabetes as assessed by skin autofluorescence. J Atheroscler Thromb. 2016;23(10):11781187.

36. Hitsumoto T. Clinical Significance of Cardio-Ankle Vascular Index as a Cardiovascular Risk Factor in Elderly Patients With Type 2 Diabetes Mellitus. J Clin Med Res. 2018;10(4):330-336.

37. Hitsumoto T. Clinical Significance of Skin Autofluorescence in Patients With Type 2 Diabetes Mellitus With Chronic Heart Failure. Cardiol Res. 2018;9(2):83-89.

38. Genevieve M, Vivot A, Gonzalez C, Raffaitin C, Barberger-Gateau P, Gin H, Rigalleau V. Skin autofluorescence is associated with past glycaemic control and complications in type 1 diabetes mellitus. Diabetes Metab. 2013;39(4):349-354.

39. Isami F, West BJ, Nakajima S, Yamagishi SI. Association of advanced glycation end products, evaluated by skin autofluorescence, with lifestyle habits in a general Japanese population. J Int Med Res. 2018;46(3):1043-1051.

40. He YM, Feng L, Huo DM, Yang ZH, Liao YH. Enalapril versus losartan for adults with chronic kidney disease: a systematic review and meta-analysis. Nephrology (Carlton). 2013;18(9):605-614.

41. Yamashita K, Kondo T, Muramatsu T, Matsushita K, Nagahiro T, Maeda K, Shintani S, et al. Effects of valsartan versus amlodipine in diabetic hypertensive patients with or without previous cardiovascular disease. Am J Cardiol. 2013;112(11):1750-1756.

42. Holtkamp FA, de Zeeuw D, de Graeff PA, Laverman GD, 
Berl T, Remuzzi G, Packham D, et al. Albuminuria and blood pressure, independent targets for cardioprotective therapy in patients with diabetes and nephropathy: a post hoc analysis of the combined RENAAL and IDNT trials. Eur Heart J. 2011;32(12):1493-1499.

43. Kim-Mitsuyama S, Soejima H, Yasuda O, Node K, Jinnouchi H, Yamamoto E, Sekigami T, et al. Cardiovascular and renal protective role of angiotensin blockade in hypertension with advanced CKD: a subgroup analysis of ATTEMPT-CVD randomized trial. Sci Rep. 2018;8(1):3150.
44. Miyoshi T, Doi M, Hirohata S, Kamikawa S, Usui S, Ogawa H, Sakane K, et al. Olmesartan reduces arterial stiffness and serum adipocyte fatty acid-binding protein in hypertensive patients. Heart Vessels. 2011;26(4):408413.

45. Kinouchi K, Ichihara A, Sakoda M, Kurauchi-Mito A, Murohashi-Bokuda K, Itoh H. Effects of telmisartan on arterial stiffness assessed by the cardio-ankle vascular index in hypertensive patients. Kidney Blood Press Res. 2010;33(4):304-312. 